\title{
Mec A gene and methicillin-resistant Staphylococcus aureus (MRSA) isolated from dairy farms in East Java, Indonesia
}

\author{
SANCAKA CHASYER RAMANDINIANTO ${ }^{1}$, ASWIN RAFIF KHAIRULLAH ${ }^{2}$, MUSTOFA HELMI EFFENDI ${ }^{3,4, v}$ \\ ${ }^{1}$ Program of Animal Diseases and Veterinary Public Health, Faculty of Veterinary Medicine, Universitas Airlangga. Jl. Mulyorejo, Surabaya 60115, East \\ Java, Indonesia \\ ${ }^{2}$ Doctoral Program in Veterinary Science, Faculty of Veterinary Medicine, Universitas Airlangga. Jl. Mulyorejo, Surabaya 60115, East Java, Indonesia \\ ${ }^{3}$ Department of Veterinary Public Health, Faculty of Veterinary Medicine, Universitas Airlangga. J1. Mulyorejo, Surabaya 60115, East Java, Indonesia \\ ${ }^{4}$ Halal Research Center, Universitas Airlangga. Jl. Mulyorejo, Surabaya 60115, East Java, Indonesia. Tel./fax.: +62-31-5915551, \\ vemail: mheffendi@yahoo.com
}

Manuscript received: 27 May 2020. Revision accepted: 13 July 2020

\begin{abstract}
Ramandinianto SC, Khairullah AR, Effendi MH. 2020. MecA gene and methicillin-resistant Staphylococcus aureus (MRSA) isolated from dairy farms in East Java, Indonesia. Biodiversitas 21: 3562-3568. Milk Borne Disease (MBD) can be caused by a variety of pathogenic bacteria, one of which is Staphylococcus aureus which has a large impact on aspects of public health. The therapy used to treat staphylococcal infection is Oxacillin preparations that can inhibit bacterial wall synthesis, but the adaptation of the mecA gene to staphylococcal cassette chromosome mec (SCCmec) causes the emergence of strains of methicillin-resistant $S$. aureus (MRSA). The purpose of this study was to detect the level of MRSA strain contamination in dairy cows in East Java by comparing the mecA gene, Oxacillin, and Cefoxitin Disc Diffusion Methods and Oxacillin Resistance Screen Agar (ORSA) detection methods. A total of 150 cow's milk samples were taken at 3 village dairy farms in East Java, samples were added to the enrichment media Buffer Pepton Water (BPW) and then isolates were planted and purified using Mannitol Salt Agar (MSA). The detection of MRSA was carried out by the Kirby Bauer disc diffusion preparation Cefoxitin $30 \mu \mathrm{g}$ and Oxacillin $30 \mu \mathrm{g}$ then confirmed by ORSA and the presence of mecA gene by the polymerase chain reaction (PCR) method. The results showed that from a total of 92 S. aureus isolates using Oxacillin disc test, 24 resistant isolates were obtained, using Cefoxitin disc test, 17 isolates were obtained, and using the ORSA test 18 MRSA isolates were obtained. MRSA isolates tested by PCR obtained evidence of 2 isolates of mecA gene. It can be concluded that the Oxacillin disc test was the highest sensitivity for detecting MRSA strain isolate, however, mecA gene was the golden standard to detect MRSA on the dairy farms.
\end{abstract}

Keywords: Cefoxitin disc, milk-borne disease, mecA gene, MRSA, Oxacillin disc, ORSA

\section{INTRODUCTION}

Milk borne diseases (MBD) are a very important problem in the public health sector which can be caused by a variety of pathogenic bacteria, one of which is Staphylococcus aureus. S. aureus opportunistic pathogens that are often found in humans and animals, these bacteria can cause a diverse spectrum of diseases from minor skin infections to systemic such as pneumonia and meningitis (Jangra and Singh 2010). Some researchers suggest that $S$. aureus can be transmitted to humans through contamination of milk, unprocessed milk, and milk products (Seifu et al. 2004; Swetha et al. 2017). S. aureus is commonly found in the skin and mucosa of ruminants, which have sub-clinical or clinical mastitis which is a source of contamination in dairy products (Sasidharan et al. 2011).

A research report reveals that the presence of multiple antibiotic resistance from $S$. aureus creates new problems for the world of health practitioners and researchers (Motamedi et al. 2010). There are studies on phenotypic and genotypic antibiotic resistance stating that since 1962 methicillin-resistant Staphylococci (MRS) have been found where the first case of methicillin-resistant Staphylococcus aureus (MRSA) has occurred in humans but has now been detected in animals (Kumar and Prasad 2010; ChajęckaWierzchowska et al. 2015). MRSA resistance to betalactam antibiotics is caused by various mechanisms, one of which is the production of unusual penicillin-binding protein (PBP), which forms PBP2 thereby weakening the affinity for the antibiotic $\beta$-lactam expressed by the mecA gene (Katayama et al. 2000). MecA gene detection using the polymerase chain reaction (PCR) method is the gold standard for detecting MRSA, but cannot be done in all clinical laboratories due to various facilities, capabilities and costs (Fernandes et al. 2005). The difficulty of using PCR in an effort to detect the presence of MRSA can be reduced by using Cefoxitin disc diffusion, Oxacillin disc diffusion combination of Oxacillin Resistance Screen Agar (ORSA) (Tyansningsih et al. 2019; Decline et al. 2020).

The purpose of this study was to detect and evaluate the level of MRSA contamination in dairy cow milk in East Java and to compare the phenotypic detection method using screening using Cefoxitine disc diffusion, Oxacillin disc diffusion combination of Oxacillin Resistance Screen Agar (ORSA) and confirm genotypically using PCR to detect the MecA gene. The sensitivity and specificity of the test will show the effectiveness and ease of application of the 
MRSA strain detection method. Also, this research information is very important to support strategic and technical decision making by relevant institutions for mitigation and prevention of impacts on aspects of public health in food safety.

\section{MATERIALS AND METHODS}

\section{Ethical clearance}

Raw milk was used in this study, hence ethical clearance was not necessary. Raw milk samples were collected from three dairy farms in East Java Province, Indonesia, namely Batu, Pasuruan, and Probolinggo districts.

\section{Sampling}

Total samples of 150 dairy cows were collected from 3 Village Unit Cooperatives in Probolinggo, Batu, and Pasuruan areas during October-November 2019. Dairy cows milk collected directly from milk can and as many as $15 \mathrm{~mL}$ were collected in centrifuge tubes of $50 \mathrm{~mL}$ (Biologix, BD-T0034). Samples were taken $1 \mathrm{~mL}$ aseptically to be put into $10 \mathrm{~mL}$ containing $4 \mathrm{~mL}$ of buffered water peptone buffer media (Oxoid, CM0509) using Syringe 3CC (AKD 20902900277) then incubated at $37 \mathrm{oC}$ for 24 hours with an incubator (Isuzu Model 2-2195, Jica) (Thaker et al. 2013).

\section{Bacteria isolation and identification}

Samples produced from enrichment media were cultured and purified on Mannitol Salt Agar media (HiMedia Pvt.Ltd, M118) and incubated at $37{ }^{\circ} \mathrm{C}$ for 24 hours. Identification was done by examination based on morphological cultural characteristics, than microscopic examination using Gram's method of staining which shows Gram-positive bacteria in the form of coccus and clustering (Effendi et al. 2018). Biochemical tests were carried out to confirm the $S$. aureus species with the catalase test and coagulase test (Effendi et al. 2019). Catalase tests were carried out by dripping hydrogen peroxide $\left(\mathrm{H}_{2} \mathrm{O}_{2}\right) 3 \%$ on clean glass objects and mixing with ose of the 1 colony (Tyasningsih et al. 2019). Coagulase test was carried out with Coagulase slide test was given $50 \mu \mathrm{l}$ rabbit blood plasma dripped on a glass object, then mixed with 1 ose of a bacterial colony, and Coagulase tube test using $200 \mu \mathrm{l}$ blood plasma was added with as much as 3-4 isolate colonies then incubated at $37^{\circ} \mathrm{C}$ for 24 hours (Effendi et al. 2019).

\section{Oxacillin and Cefoxitin disc diffusion methods}

The test was carried out referring to the Clinical and Laboratory Standards Institute guidelines where S. aureus was tested for susceptibility to the $30 \mu \mathrm{g}$ Cefoxitin and Oxacillin $30 \mu \mathrm{g}$ (Oxoid) antibiotic preparations on Muller Hinton agar plates (Oxoid, CM0337) (CLSI 2018). Isolates that have been isolated and identified will be purified on Mannitol Salt Agar (HiMedia Pvt. Ltd., M118) and incubated at $37{ }^{\circ} \mathrm{C}$ for 24 hours as a $0.5 \mathrm{Mc}$ Farland's suspension and subsequently taken using Sterile Cotton
Swab S (AKD 10903610549). The swab was streaked evenly on the surface of the Muller Hinton agar medium (Oxoid, CM0337). Cefoxitin $30 \mu \mathrm{g}$ and Oxacillin $30 \mu \mathrm{g}$ were placed side by side with a distance of $4.5 \mathrm{~cm}$ on Muller Hinton agar medium which had been inoculated with isolate and then incubated $37{ }^{\circ} \mathrm{C}$ for 24 hours and measured the inhibition zone. In the anefoxitin disc diffusion test inhibition zone $\leq 21 \mathrm{~mm}$ is methicillinresistant (MR) isolate, whereas in Oxacillin disc diffusion test isolates with an inhibition zone $\leq 10 \mathrm{~mm}$ is $\mathrm{MR}$.

\section{Oxacillin resistance screen agar test}

Oxacillin Resistance Screen Agar test (ORSA Test) is carried out referring to the Clinical and Laboratory Standards Institute guidelines aimed at confirming MRSA which is MR from Oxacillin and Cefoxitin Disc Diffusion Methods (CLSI 2018; Decline et al. 2020). Isolates were taken by several colonies to be used as a suspension of 0.5 Mc Farland and then by using Sterile Cotton Swab S (Onemed, AKD 10903610549) and making smears on the Oxacillin Screen Agar Base (HiMedia Pvt. Ltd., M1415) added with Oxacillin Resistant Selective Supplement (Supplements, HiMedia Pvt. Ltd., FD191).

\section{Detection of the mecA gene}

All confirmed $S$. aureus isolates were MRSA by the ORSA test were tested using PCR to detect the presence of the mecA gene (Rahmaniar et al. 2020). The DNA extraction process was carried out according to the QIAamp DNA Mini Kit protocol (51304 \& 51306), where previously the isolate was purified first on Mannitol Salt Agar (HiMedia Pvt. Ltd, M118) and inoculated on Muller Hinton agar (Oxoid, CM0337). The primers used namely mecA F: 5 '-GAA ATG GAA CGT CCG ATA A-3' and mecA R: 5 '-CCA ATT CCA CAT TGT TTC CTA A-3' (Rajabiani et al. 2014; Rahmaniar et al. 2020). The master mixture uses GoTaq ${ }^{\circledR}$ Green Master Mix (Promega, 9PIM712) which is a premixed ready-to-use solution containing Taq DNA polymerase, dNTPs, $\mathrm{MgCl}_{2}$, and buffers reaction. DNA was amplified using a Thermal Cycler T100 machine (Bio-Rad, 186-1096) with an initial denaturation step of 4 min at $94{ }^{\circ} \mathrm{C}$ than 35 cycles at $94^{\circ} \mathrm{C}$ for $1 \mathrm{~min}$, annealing at $62{ }^{\circ} \mathrm{C}$ for $1 \mathrm{~min}$, then the extension at $72^{\circ} \mathrm{C}$ for $45 \mathrm{~s}$. The final extension is carried out for $5 \mathrm{~min}$ at $72^{\circ} \mathrm{C}$. Amplicons were processed with electrophoreses, where the gel will be visualized in ultraviolet illumination (Rahmaniar et al. 2020). Positive tests showed PCR products in the $310 \mathrm{bp}$ band, with MRSA ATCC BAA 1026 as a positive control and S. aureus ATCC 25923 as a negative control.

\section{RESULTS AND DISCUSSION}

The test results found that there were $92(61 \%) S$. aureus isolates from 150 milk samples taken in 3 regions in East Java, Indonesia (Batu, Pasuruan, and Probolinggo districts) based on morphological characteristics and biochemical tests, as shown in Table 1. S. aureus has phenotypic characteristics of colonies on Mannitol Salt 
Agar (MSA) media, which changes the color of the media from red to yellow which indicates mannitol fermentation while the colonies have varying pigments including white, yellow, and orange (Figure 1) (Effendi et al. 2019). Gram's method of staining test showed the form of the grampositive colony and shaped like the genus Staphylococcus which was then confirmed by catalase tests and coagulase tests so that it was found that $61 \%$ of samples confirmed the presence of $S$. aureus contamination.

Methicillin-resistant (MR) S. aureus based on disc diffusion method on Muller Hinton Agar (MHA) media showed that the total results of isolate resistance to Oxacillin preparations were $26 \%$ with the highest percentage detected in Probolinggo, as well as the results of isolate resistance to Cefoxitin preparations which was found to be $18.5 \%$ and Probolinggo was $26 \%$. the highest detected percentage, as shown in Table 2 and Figure 2. The results obtained showed that there were no isolates that were only resistant to Cefoxitin in the disk diffusion method, all isolates that were detected were resistant to Cefoxitin were also identified to be resistant to Oxacillin but there were isolates that were Oxacillin resistant and still sensitive to Cefoxitin, as shown in Table 3. The phenotypic MR test confirmation was continued using the Oxacillin Resistance Screen Agar (ORSA) test with a blue culture indicator showing positive confirmation results while the

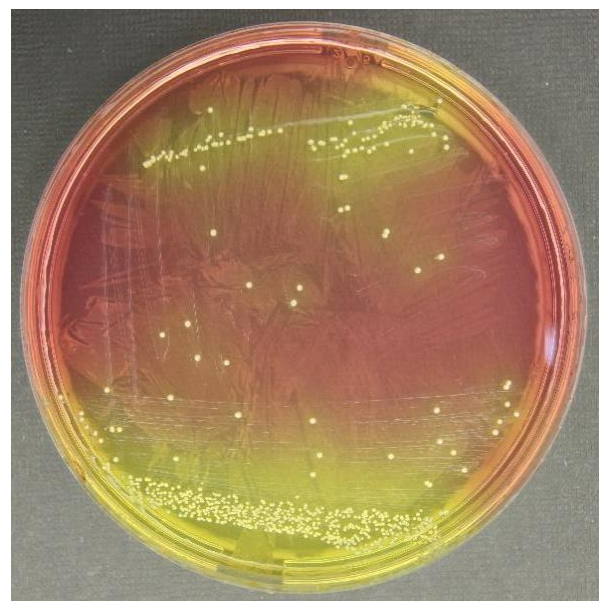

Figure 1. The results of positive yellow Mannitol Fermentation and $S$. aureus colonies appear mucoid white on Mannitol Salt Agar medium (HiMedia Pvt. Ltd, M118) (Cannon 600D DSLR). $72 \times 72$ dpi white color results were negative confirmation results (Rahmaniar et al. 2020). ORSA test showed that of $24 \mathrm{~S}$. aureus isolates resistant to Oxacillin, the disc diffusion method was found that was positively confirmed MRSA were 18 isolates, as shown in Table 3 .

Isolates confirmed as MRSA phenotypically by the ORSA method were further tested genotypically by the PCR method to detect the presence of the mecA gene in the isolate. A total of 18 MRSA isolates confirmed by ORSA were tested using the PCR method and 2 isolates (11.1\% of the tested isolates) were detected positive mecA gene, so the 2 isolates were genotypically confirmed as MRSA strains, as shown on Figure 3 and Figure 4. Results from PCR tests showed that the isolates detected have the mecA gene which has resistance to Cefoxitin and Oxacillin antibiotics, as shown in Table 3.

Table 1. Positive Staphylococcus aureus isolates from milk samples

\begin{tabular}{lccc}
\hline \multicolumn{1}{c}{ Location } & $\begin{array}{c}\text { Location } \\
\text { code }\end{array}$ & Total & $\begin{array}{c}\text { Positive } \\
\text { S. aureus }(\%)\end{array}$ \\
\hline Probolinggo & $\mathrm{A}$ & 50 & $30(60 \%)$ \\
Batu & $\mathrm{H}$ & 50 & $38(76 \%)$ \\
Pasuruan & $\mathrm{G}$ & 50 & $24(48 \%)$ \\
Total & & Total & $92(61 \%)$ \\
\hline
\end{tabular}

Note: \%: Number of percentages of S. aureus in milk samples

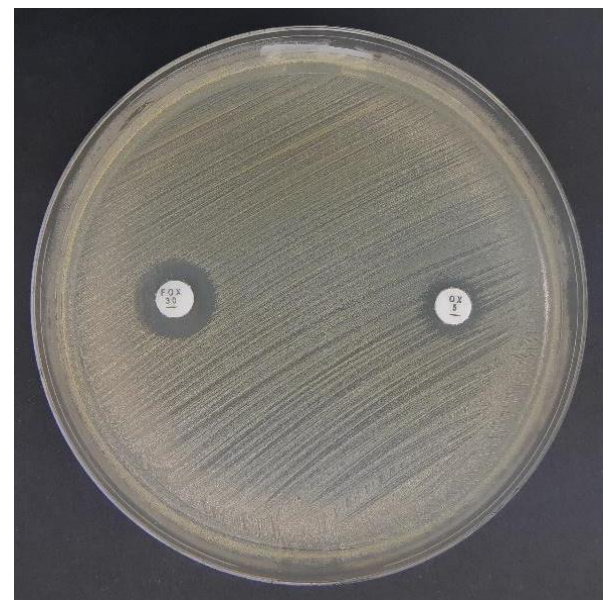

Figure 2. Cefoxitin (FOX) and Oxacillin (OX) Disc Diffusion Test in Mueller Hinton Agar (Oxoid, CM0337). FOX = Cefoxitin (Break Point 21-22*), OX = Oxacillin (Break Point 21-22*). * Clinical and Laboratory Standards Institute (Canon 600D DSLR). $72 \times 72$ dpi

Table 2. Oxacillin and Cefoxitine Disc Diffusion test of Staphylococcus aureus by location

\begin{tabular}{|c|c|c|c|c|}
\hline \multirow{3}{*}{ Location } & \multicolumn{4}{|c|}{ Staphylococcus aureus $(\mathrm{n}=92)$} \\
\hline & \multicolumn{2}{|c|}{ OX Disc Diffusion } & \multicolumn{2}{|c|}{ FOX Disc Diffusion } \\
\hline & Resistant (\%) & Sensitive (\%) & Resistant (\%) & Sensitive (\%) \\
\hline Probolinggo & $10(10.9 \%)$ & $20(21.7 \%)$ & $8(8.7 \%)$ & $22(23.9 \%)$ \\
\hline Batu & $8(8.7 \%)$ & $30(32.6 \%)$ & $6(6.5 \%)$ & $32(34.8 \%)$ \\
\hline Pasuruan & $6(6.5 \%)$ & $18(19.5 \%)$ & $3(3.3 \%)$ & $21(22.8 \%)$ \\
\hline Total & $24(26 \%)$ & $68(74 \%)$ & $17(18.5 \%)$ & $75(81.5 \%)$ \\
\hline
\end{tabular}

Note: \% (Percentage): Total percentage of positive or resistant resistant values in S. aureus isolates. FOX $=$ Cefoxitin $30 \mu \mathrm{g}$, OX $=$ Oxacillin $30 \mu \mathrm{g}$ (Oxoid) 
Table 3. Positive MRSA confirmed by OX and FOX Disc Diffusion, ORSA and $M e c A$ gene detection

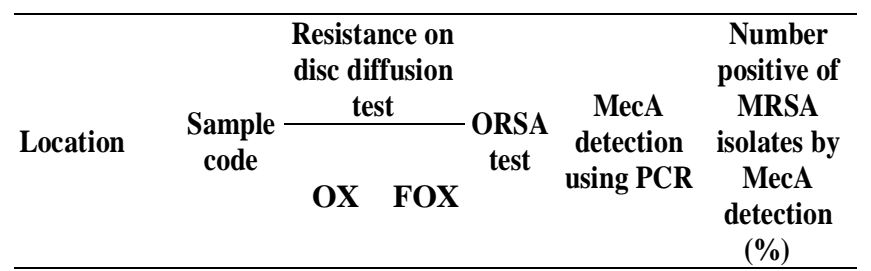

\begin{tabular}{|c|c|c|c|c|c|c|}
\hline \multirow[t]{10}{*}{ Probolinggo } & A04 & + & + & + & - & \multirow[t]{10}{*}{-} \\
\hline & A07 & + & + & + & - & \\
\hline & A17 & + & + & + & - & \\
\hline & A 21 & + & + & + & - & \\
\hline & A31 & + & + & + & - & \\
\hline & A32 & + & - & + & - & \\
\hline & A35 & + & + & - & Not tested & \\
\hline & $\mathrm{A} 40$ & + & + & - & Not tested & \\
\hline & A45 & + & + & + & - & \\
\hline & A49 & + & + & + & - & \\
\hline \multirow[t]{8}{*}{ Batu } & H02 & + & + & - & $\begin{array}{l}\text { Not } \\
\text { tested }\end{array}$ & \multirow[t]{8}{*}{$2(2.2)$} \\
\hline & $\mathrm{H} 27$ & + & + & + & + & \\
\hline & $\mathrm{H} 28$ & + & - & - & Not tested & \\
\hline & H37 & + & + & + & - & \\
\hline & $\mathrm{H} 41$ & + & - & + & - & \\
\hline & $\mathrm{H} 48$ & + & + & + & + & \\
\hline & $\mathrm{H} 49$ & + & + & + & - & \\
\hline & $\mathrm{H} 50$ & + & + & + & - & \\
\hline \multirow[t]{6}{*}{ Pasuruan } & G06 & + & + & + & - & \multirow{6}{*}{-} \\
\hline & G16 & + & + & - & Not tested & \\
\hline & G18 & + & - & - & Not tested & \\
\hline & $\mathrm{G} 24$ & + & - & + & - & \\
\hline & G33 & + & + & + & - & \\
\hline & G37 & + & - & + & - & \\
\hline
\end{tabular}

Total number positive of MRSA Isolate by $\mathrm{MecA}$ $2(2.2)$ detection

Note: FOX: Cefoxitin $30 \mu \mathrm{g}$, OX: Oxacillin $30 \mu \mathrm{g}$ (Oxoid). \% (percentage): Total positive percentage of MRSA from $S$. aureus isolates by PCR at the sampling location. + : Resistant, No: No tested

\section{Discussion}

Milk-borne diseases (MBD) are problems that must be controlled in the public health sector but not only affect human health but also have an impact on the economic sector. Research on antimicrobial drug resistance of $S$. aureus reports that related dairy product contamination is not only limited to developing countries but also occurs in developed countries. Some researchers report that bacterial outbreaks in milk and dairy products in countries going around 2-6\% (De Buyser et al. 2001; Sasidharan et al. 2011). Improper food handling and unhygienic practices during the production process, packaging to distribution have a significant role in the occurrence of food poisoning (De Buyser et al. 2001). Another researcher stated that cow's milk can transmit various pathogens including Staphylococci strains (Angelillo et al. 2000).

Staphylococcus aureus is a pathogenic agent that can cause various infectious diseases from cutaneous to systemic infections in immunocompetent hosts, resulting in death (Vyas et al. 2015). In this study of 150 milk samples found as many as $61 \%$ detected S. aureus contamination, this percentage was higher compared to Swetha et al. (2017) which isolates $57 \%$ of Staphylococci strains, of which $73.6 \%$ were $S$. aureus; and reports by VyletěloVá et al. (2011) that isolates Staphylococci strains as much as $47.5 \%$ of dairy cow's milk, while the dominant strain is $S$. aureus with $46.4 \%$ of the total Staphylococci strains isolates. This study has a purposive design conducted specifically to detect the presence of Staphylococci strains in dairy cows farms that have low hygiene milking thereby increasing the potential for contaminants in cows milk. In line with this, research in North India states that differences in the number of isolates found can be influenced by differences in study design such as population and geographic distribution of samples, types of antibiotics used, and infection control practices (Oberoi et al. 2012).

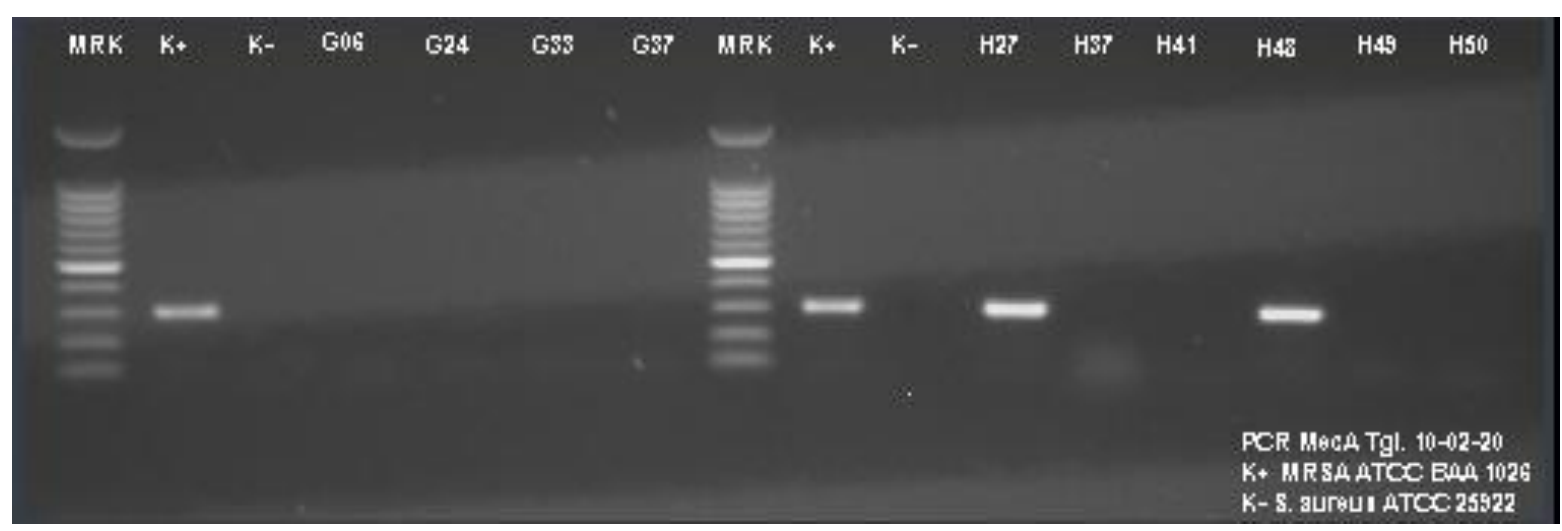

Figure 3. MecA PCR results with positive bands at 310 bp. MRK Line: 100-bp molecular-weight markers, Line K +: MRSA ATCC BAA 1026 (Positive Control), Line K-: Staphylococcus aureus ATCC 25923 (Negative Control), Line H27 and H48: Positive isolate for mecA gene from Batu, Line G06, G24, G33, G37, H37, H41, H49, and H50: Negative isolate for mecA gene. 


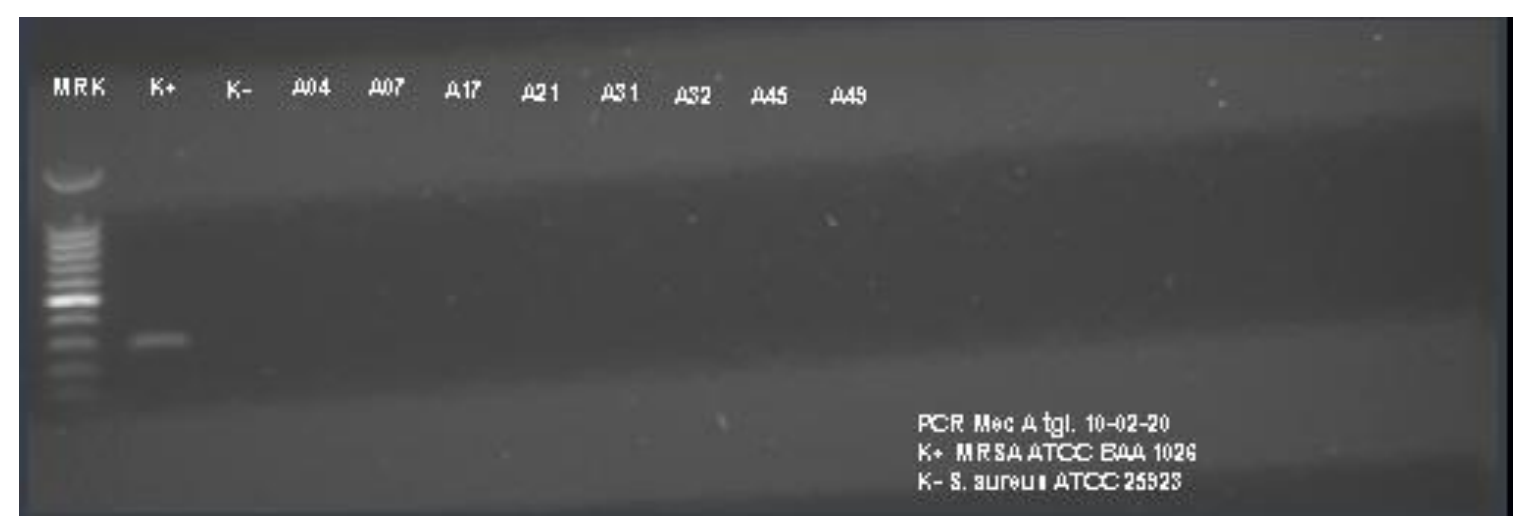

Figure 4. Meca PCR results with positive bands at 310 bp. MRK Line: 100-bp molecular-weight markers, Line K +: MRSA ATCC BAA 1026 (Positive Control), Line K-: Staphylococcus aureus ATCC 25923 (Negative Control), Line A04-A49: Negative isolate for mecA gene

Staphylococcus aureus problem develops with the presence of methicillin resistance (MR) so that the methicillin resistance group Staphylococcus aureus (MRSA) has resistant properties to all $\beta$-lactam antibiotics including cephalosporins and monobactams which are important antibiotic groups for the treatment of staphylococcal infections (Graveland et al. 2011; Vyas et al. 2015). MRSA infection not only causes therapeutic problems but also makes it easy to spread, so a rapid and early diagnosis and accurate identification of MRSA are needed (Yamazumi et al. 2001). In this study, several $S$. aureus isolates were detected that were resistant to the preparation of Oxacillin by $26 \%$ and Cefoxitin $18.5 \%$ in the disc diffusion method. Brown and Walpole (2001) state that basically MRSA detection with phenotypic methods still has not shown optimal results and mecA genotypic tests are still the main recommendation even though it cannot be applied to routine tests. So that accurate, rapid, and cost-effective identification of MRSA can use phenotypic methods (Krishnan et al. 2002). Cefoxitin disc diffusion and Oxacillin disc diffusion have the same sensitivity level of $100 \%$, specificity where Cefoxitin disc diffusion is $92.59 \%$ while Oxacillin disc diffusion is $74.07 \%$ (Vyas et al. 2015). This value is in line with various studies that have been reported by Oberoi et al. (2012), Velasco et al. (2005), Tiwari et al. (2009), and Mathews et al. (2010). However, several studies suggest that the Cefoxitin disc method has a better level of sensitivity compared to the Oxacillin disc method in detecting MRSA, so the Oxacillin disc method still has a level of false positives (Skov et al. 2003; Boubaker et al. 2004; Velasco et al. 2005). Vyas et al. (2015) state that the rate of false positives can be influenced by the hyperproduction of $\beta$-lactamase, giving rise to Oxacillin resistance phenotypic expression but does not have a genetic resistant mechanism.

In this study, all isolates that were detected to be resistant to Cefoxitin also had resistance to Oxacillin, but some isolates were detected to be resistant to Oxacillin and sensitive to Cefoxitin. All isolates detected were resistant to Oxacillin confirmed by the ORSA test, in line with Datta et al. (2011) which stated that the ORSA test had $100 \%$ specificity and from this study found $18(75 \%)$ isolates out of 24 isolates expressed positive results as MRSA. The sensitivity level will validate the homogeneity of the resistant strains tested while specificity will be related to the borderline of the minimum inhibitory concentration (MIC) of a strain (Swenson et al. 2001). ORSA positive isolates were all genotypically tested using PCR to detect the presence of the mecA gene, which became the golden standard for detecting MRSA. Two isolates from Batu were detected having the mec A gene, where the isolates also had positive results in all phenotypic methods (Cefoxitin and Oxacillin disc diffusion and ORSA), these results were similar to the results of research conducted by researchers from Southern Province of India(Venugopal et al. 2019). Cefoxitin is a good inducer for expressing the presence of the mecA gene because it can increase the expression of the protein penicillin-binding protein $2 \mathrm{a}$ ( $\mathrm{PBP} 2 \mathrm{a}$ ) encoded by the mecA gene, the statement was also in accordance with Cauwelier et al. (2004) and Velasco et al. (2005).

In this study, it can be concluded that the presence of milk contamination by MRSA can be caused by various factors, one of which is low hygiene milking. Besides, MRSA contamination is very dangerous for public health aspects, which will increase the potential spread of Staphylococcal infection which is difficult to treat. So the urgency of clinical microbiology laboratories identify is very important to be able to do accurate, rapid and costeffective identification of MRSA contamination in transmission media such as food from animal origin. Genotypic detection using PCR to detect the presence of the mecA gene is the golden standard of MRSA detection, but in a laboratory that unable to do molecular testing can use Cefoxitin disk diffusion as a marker for MR detection. This is based on the ability of the Cefoxitin disc diffusion test in detecting mecA gene expression so that it can be a solution as an MRSA screening instrument more effectively and efficiently in cost, technical applications, and media preparation. 


\section{ACKNOWLEDGEMENTS}

This study was supported in part with the Penelitian Hibah Mandat funding from Airlangga University, Surabaya, Indonesia in the fiscal year 2019.

\section{REFERENCES}

Angelillo IF, Viggiani NMA, Rizzo L, Bianco A. 2000. Food handlers and foodborne diseases: Knowledge attitudes and reported behavior in Italy. J Food Prot 63 (3): 381-385. DOI: 10.4315/0362-028x-63.3.381

Boubaker, IBB, Ben Abbes R, Ben Abdallah H, Mamlouk K, Mahjoubi F, Kammoun A, Hammami A, Ben Redjeb S. 2004. Evaluation of a Cefoxitin disk diffusion test for the routine detection of methicillinresistant Staphylococcus aureus. Clin Microbiol Infect 10 (8): 762 765. DOI: 10.1111/j.1469-0691.2004.00919.x

Brown DFJ, Walpole E. 2001. Evaluation of the Mastalex latex agglutination test for methicillin resistance in Staphylococcus aureus grown on different screening media. J Antimicrob Chemoth 47 (2): 187-189. DOI: $10.1093 / \mathrm{jac} / 47.2 .187$

Cauwelier B, Gordts B, Descheemaecker P, Van Landuyt H. 2004 Evaluation of a disk diffusion method with Cefoxitin $(30 \mu \mathrm{g})$ for detection of methicillin-resistant Staphylococcus aureus. Eur J Clin Microbiol Infect Dis 23: 389-392. DOI: $10.1007 / \mathrm{s} 10096-004-1130-8$

Chajęcka-Wierzchowska W, Zadernowska A, Nalepa B, Sierpinska M, Łaniewska-Trokenheim L. Coagulase-negative Staphylococci (CoNS) isolated from ready to eat food of animal origin phenotypic and genotypic antibiotic resistance. Food Microbiol 46: 222-226. DOI: 10.1016/j.fm.2014.08.001

CLSI [Clinical and Laboratory Standards Institute]. 2018. Performance Standards for Antimicrobial Susceptibility Testing. 28th ed. Clinical and Laboratory Standards Institute, Wayne, PA.

Datta P, Gulati N, Singla N, Vasdeva HR, Bala K, Chander J, Gupta V. 2011. Evaluation of various methods for the detection of meticillinresistant Staphylococcus aureus strains and susceptibility patterns. J Med Microbiol 60 (11): 1613-1616. DOI: 10.1099/jmm.0.032219-0.

De Buyser ML, Dufour B, Maire M, Lafarge V. 2001. Implication of milk and milk products in food-borne diseases in France and in different industrialized countries. Intl J Food Microbiol 67 (1-2): 1-17. DOI: 10.1016/s0168-1605(01)00443-3

Decline V, Effendi MH, Rahmaniar RP, Yanestria SM, Harijani N. 2020 Profile of antibiotic-resistant and presence of methicillin-resistan Staphylococcus aureus from nasal swab of dogs from several animal clinics in Surabaya, Indonesia. Intl J One Health 6 (1): 90-94. DOI: 10.14202/IJOH.2020.90-94.

Effendi MH, Hisyam MAM, Hastutiek P, Tyasningsih W. 2019. Detection of coagulase gene in Staphylococcus aureus from several dairy farms in East Java, Indonesia, by polymerase chain reaction. Vet World 12 (1): 68-71. DOI: 10.14202/vetworld.2019.68-71.

Effendi MH, Oktavianto A, Hastutiek P. 2018. Tetracycline resistance gene in Streptococcus agalactiae isolated from bovine subclinical mastitis in Surabaya, Indonesia. Philippine J Vet Med 55: 115-120.

Fernandes CJ, Fernandes LA, Collignon P. 2005. Cefoxitin resistance as a surrogate marker for the detection of methicillin-resistant Staphylococcus aureus. J Antimicrob Chemother 55 (4): 506-510. DOI: $10.1093 / \mathrm{jac} / \mathrm{dki052}$

Graveland H, Duim B, van Duijkeren E, Heederik D, Wagenaar JA. 2011. Livestock associated methicillin-resistant Staphylococcus aureus in animals and humans. Intl J Med Microbiol 301 (8): 630-4. DOI: 10.1016/j.ijmm.2011.09.004.

Motamedi H, Mirzabeigi H, Shirali T. 2010. Determining of antibiotics resistance profile in Staphylococcus aureus isolates. Asian Pac J Trop Med 3 (9): 734-737. DOI: 10.1016/S1995-7645(10)60176-9.

Jangra P, Singh A. 2010. Staphylococcus aureus $\beta$-hemolysisn neutralizing single domain antibody isolated from phage display library of Indian desert camel. Asian Pacific J Trop Med 3 (1): 1-7. DOI: 10.1016/S1995-7645(10)60020-X

Katayama Y, Ito T, Hiramatsu K. 2000. A new class of genetic element, Staphylococcus cassette chromosome Mec, encodes methicillin resistance in Staphylococcus aureus. Antimicrob Agents Chemother 44 (6): 1549-1555. DOI: 10.1128/aac.44.6.1549-1555.2000
Krishnan PU, Miles K, Shetty N. 2002. Detection of methicillin and mupirocin resistance in Staphylococcus aureus isolates using conventional and molecular methods: A descriptive study from a burn unit with high prevalence of MRSA. J Clin Pathol 55 (10): 745-748. DOI: $10.1136 /$ jcp.55.10.745.

Kumar R, Prasad A. 2010. Detection of E. coli and Staphylococcus in milk and milk products in and around Pantnagar. Vet World 3 (11): 495-496.

Mathews AA, Thomas M, Appalaraju B, Jayalakshmi J. 2010. Evaluation and comparison of tests to detect methicillin-resistant $S$. aureus. Indian J Pathol Microbiol 53 (1): 79-82. DOI: 10.4103/03774929.59189.

Oberoi L, Kaur K, Aggarwal A. 2012. Prevalence and antimicrobial susceptibility pattern of methicillin-resistant Staphylococcus aureus (MRSA) in a rural tertiary care hospital in North India. Intl J Appl Biol Pharm Technol 3: 200-205.

Rahmaniar RP, Yunita MN, Effendi MH, Yanestria SM. 2020. Encoding gene for methicillin-resistant Staphylococcus aureus (MRSA) isolated from nasal swab of dogs. Indian Vet J 97 (2): 37-40.

Rajabiani A, Kamrani F, Boroumand MA, Saffar H. 2014. MecA mediated resistance in Staphylococcus aureus in a referral hospital, Tehran, Iran. Jundishapur J Microbiol 7 (4): e9181. DOI: $10.5812 /$ jjm. 9181

Sasidharan S, Prema B, Yoga Latha LL. 2011. Antimicrobial drug resistance of Staphylococcus aureus in dairy products. Asian Pac J Trop Biomed 1 (2): 130-132. DOI: 10.1016/S2221-1691(11)60010-5

Seifu E, Buys EM, Donkin, Petzer IM. 2004. Antibacterial activity of lactoperoxidase system against foodborne pathogen in Saanen and South African indigenous goat milk. Food Control 15 (6): 447-452. DOI: 10.1016/S0956-7135(03)00120-8.

Skov R, Smyth R, Clausen M, Larsen AR, Frimodt-Møller N, OlssonLiljequist B, Kahlmeter G. 2003. Evaluation of a Cefoxitin $30 \mathrm{mg}$ disc on Iso-Sensitest agar for detection of methicillin-resistant Staphylococcus aureus. J Antimicrob Chemother 52 (2): 204-207. DOI: $10.1093 / \mathrm{jac} / \mathrm{dkg} 325$

Swenson JA, Spargon J, Tenover FC, Ferraro MJ. 2001. Optimal inoculation methods and quality control for the NCCLS Oxacillin agar screen test for detection of Oxacillin resistance in Staphylococcus aureus. J Clin Microbiol 39 (10): 3781-3784. DOI: 10.1128/JCM.39.10.3781-3784.2001.

Swetha CS, Supriya RA, Goud SS, Babu AJ, Rao TM. 2017. A study on the prevalence of zoonotic important methicillin-resistant and vancomycin-resistant Staphylococcus aureus (MRSA \& VRSA) and coagulase-negative Staphylococci (MR-CNS \& VR-CNS) in raw milk samples of Tirupati, Andhra Pradesh. Pharma Innov Intl J 6 (9): 17 24

Thaker HC, Brahmbhatt MN, Nayak JB. 2013. Isolation and identification of Staphylococcus aureus from milk and milk products and their drug resistance patterns in Anand, Gujarat. Vet World 6 (1): 10-13. DOI: 10.5455/vetworld.2013.10-13

Tiwari HK, Sapkota D, Das AK, Sen MR. 2009. Assessment of different methods to detect methicillin-resistant Staphylococcus aureus. Southeast Asian J Trop Med Public Health 40 (4): 801-806.

Tyasningsih W, Effendi MH, Budiarto B, Syahputra IR. 2019. Antibiotic resistance to Staphylococcus aureus and methicillin-resistant Staphylococcus aureus (MRSA) isolated from dairy farms in Surabaya, Indonesia. Indian Vet J 96 (11): 27-31.

Velasco D, del Mar Tomas M, Cartelle M, Beceiro A, Perez A, Molina F, Moure R, Villanueva R, Bou G. 2005. Evaluation of different methods for detecting methicillin (Oxacillin) resistance in Staphylococcus aureus. J Antimicrob Chemother 55 (3): 379-382. DOI: $10.1093 / \mathrm{jac} / \mathrm{dki0} 17$

Venugopal N, Mitra S, Tewari R, Ganaie F, Shome R, Rahman H, Shome BR. 2019. Molecular detection and typing of methicillin-resistant Staphylococcus aureus and methicillin-resistant coagulase-negative Staphylococci isolated from cattle, animal handlers, and their environment from Karnataka, Southern Province of India. Vet World 12 (11): 1760-1768. DOI: 10.14202/vetworld.2019.1760-1768.

Vyas A, Sharma M, Kumar S, Kumar M, Mehra SK. 2015. A comparative study of Oxacillin screen agar, Oxacillin disc diffusion and Cefoxitin disc diffusion, Oxacillin E-test method for routine screening of methicillin-resistant Staphylococcus aureus. Intl J Cur Res Rev 7 (10): 55-60.

VyletěloVá M, VlkoVá H, Manga I. 2011. Occurrence and characteristics of methicillin-resistant Staphylococcus aureus and methicillinresistant coagulase-negative Staphylococci in raw milk 
manufacturing. Czech J Food Sci 29: S11-S16. DOI: 10.17221/4443CJFS

Yamazumi T, Marshall SA, Wilke WW, Diekema DJ, Pfaller MA, Jones RN. 2001. Comparison of the Vitek gram-positive susceptibility 106 cards and MRSA screen latex agglutination test for determining Oxacillin resistance in clinical bloodstream isolates of Staphylococcus aureus. J Clin Microbiol 39 (1): 53-56. DOI: 10.1128/JCM.39.1.5356.2001 . 